\title{
A industrialização brasileira antes de 1930: uma contribuição sobre a evolução da indústria de máquinas e equipamentos no estado de São Paulo, 1900-1920 ^
}

\author{
Michel Deliberali Marson \\ Professor - Universidade Federal de Alfenas - Instituto de Ciências Sociais Aplicadas \\ Endereço: Avenida Celina Ferreira Ottoni, 4000 - Varginha - Minas Gerais/MG - Brasil \\ CEP: 37048-395 - E-mail: michelmarson@yahoo.com.br
}

Recebido em 03 de julho de 2013. Aceito em 02 de agosto de 2014.

\begin{abstract}
Resumo
O objetivo do presente trabalho é trazer luz para a divergência da historiografia econômica sobre a produção, investimento e lucratividade da indústria de máquinas e equipamentos brasileira e paulista no período da Primeira Guerra Mundial por meio do exame da evolução dessa indústria entre 1900 a 1920, utilizando fontes primárias originais. As principais fontes são os contratos, alterações e distratos arquivados na Junta Comercial de São Paulo para o período de 1911 a 1920. Esses contratos são os registros de constituição de empresas em sociedades de empresários de todo ramo de atividade econômica do estado de São Paulo. Os principais resultados dos efeitos da Primeira Guerra Mundial para a indústria de máquinas e equipamentos de São Paulo foram queda do investimento, aumento da produção, com aumento da demanda doméstica devido à queda das importações, e aumento da lucratividade das empresas que resultaram em um ambiente de incentivo para a fundação de novas pequenas empresas (oficinas mecânicas). Algumas dessas empresas ampliaram seu investimento no período pós-guerra.
\end{abstract}

\section{Palavras-Chave}

Indústria. Máquinas e equipamentos. São Paulo.

\begin{abstract}
The aim of this paper is to shed light on the divergence of economic historiography on production, investment and profitability of the machinery and equipment industry in Brazil and São Paulo in the period of the First World War through the evolution of the industry from 1900 to 1920 , using original primary sources. The main sources are the contracts, amendments and dissolutions filed in the Sao Paulo Trade Board between 1911 and 1920. These contracts are records of business formation in societies of entrepreneurs from every branch of economic activity in the state of São Paulo. The main

- O trabalho contou com o apoio da FAPESP e da FAPEMIG. Agradeço os comentários recebidos de Renato Colistete, Amaury Gremaud, Wilson Suzigan, Flávio Saes e Dante Aldrighi, dos participantes do $41^{\circ}$. Encontro Nacional de Economia da ANPEC, do XVI Seminário sobre a Economia Mineira, do VII Encontro de Pós-Graduação em História Econômica e 5a . Conferência Internacional de História Econômica, e dos pareceristas anônimos da revista.
\end{abstract}


results of the effects of the First World War for the machinery and equipment industry in São Paulo were decrease in investment, increased in production, rising domestic demand due to drop in imports, and increased in profitability of the companies that resulted in an environment incentive for the foundation of new small businesses (workshops). Some of these companies increased their investment post-war.

\section{Keywords}

Industry. Machinery and equipment. Sao Paulo.

\section{JEL Classification}

N76. N86. O47.

\section{Introdução}

A indústria de máquinas e equipamentos é o setor chave no processo de industrialização e desenvolvimento econômico de um país, fornecendo máquinas e equipamentos que transformam as condições de produção da agricultura e da indústria. Além disso, essa indústria é importante para o desenvolvimento econômico porque incorpora novos conhecimentos tecnológicos ao processo produtivo, por meio da introdução de novos bens de capital que elevam a produtividade e eficiência do sistema econômico. Para fins deste trabalho, a indústria de máquinas e equipamentos é definida da mesma forma em que é classificado o gênero da indústria mecânica no Censo Industrial de 1950 (FIBGE, 1955, p. 71-72). ${ }^{1}$

A indústria de máquinas e equipamentos em São Paulo teve origem no século XIX em uma economia que tinha como principal atividade a exportação de produtos primários. Há vários trabalhos que estuda-

1 Assim, a indústria de máquinas e equipamentos é constituída pela produção de máquinas motrizes não elétricas, máquinas e turbinas a vapor, rodas e turbinas hidráulicas e moinhos de vento, motores fixos de combustão interna, equipamentos para transmissões, máquinas, aparelhos e equipamentos para instalações hidráulicas, térmicas e de ventilação, bombas hidráulicas, compressores, aspiradores, exaustores e ventiladores industriais, máquinas e aparelhos de refrigeração, equipamentos para destilarias, lavanderias e cozinhas a vapor, máquinas-ferramenta e máquinas operatrizes, peças e acessórios para máquinas-ferramenta e máquinas operatrizes, máquinas e aparelhos para a lavoura e indústrias rurais, máquinas e aparelhos para lavouras (tratores, arados, cultivadores, carpideiras e congêneres), máquinas e equipamentos para as indústrias rurais (debulhadores, máquinas para beneficiamento de café, cereais e algodão, moendas de cana e congêneres), outros aparelhos agrícolas (incubadoras, pulverizadores, extintores de formigas e congêneres), montagem e reparação de máquinas e aparelhos, construção de máquinas, aparelhos e equipamentos diversos, balanças e básculas, elevadores, pontes rolantes, guinchos, talhas, guindastes e outros aparelhos para transporte e elevação de carga, construção de máquinas, aparelhos e equipamentos em geral. 
ram a evolução da indústria brasileira no período anterior e durante o compreendido pela Primeira Guerra Mundial. ${ }^{2}$ Dentre esses trabalhos, há indicações gerais sobre a evolução da indústria como um todo e também de setores específicos, como a indústria de bens de capital, especialmente máquinas e equipamentos. Entretanto, apesar dos estudos aprofundados indicarem algumas tendências importantes, há poucas evidências dos efeitos da Primeira Guerra Mundial na indústria brasileira de máquinas e equipamentos, e mais especificamente na indústria do estado de São Paulo. ${ }^{3}$

Além de poucas evidências também há divergências entre os estudos sobre os efeitos da Primeira Guerra Mundial na indústria de máquinas e equipamentos. A principal controvérsia historiográfica é se a Primeira Guerra Mundial foi favorável ou não para a incipiente produção e investimento da indústria de máquinas e equipamentos. Warren Dean (1976) e Luiz Aranha Correa do Lago et alii (1979) afirmaram que o período da Primeira Guerra Mundial foi favorável para a produção da indústria de máquinas e equipamentos. ${ }^{4} \mathrm{Com}$ a diminuição das importações de matérias-primas, o ferro velho e outros metais podiam ser reaproveitados. Como as pequenas oficinas de fundição exigiam equipamentos simples, várias oficinas foram abertas durante o período do conflito para a produção de peças e máquinas de ferro fundido (Dean, 1976, p. 106-107). Lago et alii (1979, p. 39-40) também afirmam que o período de 1915 a 1919 foi favorável à produção interna de equipamentos mais simples e substancial expansão da capacidade de produção da indústria de bens de capital. Mesmo assim, os autores são categóricos em afirmar que "fica dependendo de investigação estatística mais detalhada, talvez até mesmo ao nível dos livros das empresas, a verificação da expansão do setor de bens de capital especificamente durante a Primeira Guerra Mundial" (Lago et alii, 1979, p. 40).

${ }^{2}$ Ver Baer (1966), Simonsen (1939), Luz (1961), Prado Jr. (1959), Leff (1968), Stein (1979), Dean (1976), Villela e Suzigan (1973), Fishlow (1972), Erber et alii (1973), Cano (1975), Silva (1976), Versiani e Versiani (1977), Lago et alii (1979) e Suzigan (2000).

3 Os efeitos da Primeira Guerra Mundial sobre a indústria brasileira como um todo estão bem mapeados (ver especialmente Suzigan, 2000, p. 51-61), mas para os setores e as regiões específicas da indústria, por exemplo, a indústria de máquinas e equipamentos em São Paulo, os efeitos da Primeira Guerra não são conclusivos na historiografia econômica.

4 É importante assinalar que Dean (1976, cap. 6) tem uma conclusão pessimista sobre os efeitos da Primeira Guerra no processo de desenvolvimento industrial como um todo, mas na indústria de máquinas e equipamentos afirma que houve uma espécie de desenvolvimento industrial resultante da guerra. 
Wilson Suzigan (2000) por outro lado, vê o período da Primeira Guerra Mundial como desfavorável tanto ao investimento, como à produção da indústria metal-mecânica: ${ }^{5}$ "após registrar altos níveis no período imediatamente anterior à guerra, os investimentos na metal-mecânica caíram drasticamente durante o conflito, e só voltaram a tomar impulso a partir da década de 1920" (Suzigan, 2000, p. 298-299). Com relação aos dados de produção "durante a guerra, a produção [da indústria metal-mecânica] parece ter sido reduzida até 1918" (Suzigan, 2000, p. 299).

O objetivo deste trabalho é contribuir com a historiografia econômica da industrialização brasileira examinando a evolução da indústria de máquinas e equipamentos paulista entre 1900 a 1920, utilizando fontes primárias originais. As principais fontes são os contratos, alterações e distratos comerciais arquivados na Junta Comercial de São Paulo para o período de 1911 a 1920, publicados no Boletim da Diretoria de Indústria e Comércio da Secretaria da Agricultura, Comércio e Obras Públicas do Estado de São Paulo. Esses contratos são os registros de constituição de empresas em sociedades de empresários de todo ramo de atividade econômica do estado de São Paulo. As informações registradas nestes contratos são relativas aos nomes dos sócios, objeto do negócio, cidade, capital, nome da empresa e, em alguns registros, há a nacionalidade desses sócios. Assim, é possível saber quais e onde as empresas foram fundadas, qual era seu capital, quem eram seus sócios, possibilitando o exame da evolução da indústria no período de escassez de informações estatísticas de 1911 a 1920.

Há outras informações qualitativas que serão utilizadas como estudos específicos sobre a indústria, também disponíveis no Boletim da Indústria e Comércio, além de uma Estatística Industrial de 1918 para o interior do estado de São Paulo, publicada por partes em vários volumes do Boletim entre o final da década de 1910 e início da década de 1920.

O restante do artigo está dividido em mais cinco seções. A próxima seção analisa as interpretações sobre a evolução da indústria de máquinas e equipamentos entre 1900 a 1920. A terceira, quarta e quinta seções são as contribuições empíricas do artigo para a histo-

5 A indústria metal-mecânica é a classificação mais próxima da indústria de máquinas e equipamentos utilizada pelo autor. 
riografia econômica da industrialização no exame da indústria de máquinas e equipamentos em São Paulo entre 1900 e 1920. A sexta seção faz um balanço das principais conclusões do artigo.

\section{Interpretações sobre a evolução da indústria de máquinas e equipamentos entre 1900 a 1920}

Há um relativo consenso na historiografia econômica da indústria de máquinas e equipamentos brasileira e paulista sobre sua evolução do final do século XIX até o período anterior à Primeira Guerra Mundial. Em geral, os autores afirmaram que o crescimento da indústria de máquinas e equipamentos brasileira e principalmente a paulista estava ligado ao desenvolvimento da economia primário-exportadora. Antes dos anos 1920, os períodos de crise do setor primário-exportador refletiam negativamente no crescimento da indústria de máquinas e equipamentos paulista e períodos de prosperidade possibilitaram a evolução do setor.

Wilson Suzigan observou que o crescimento do setor metal-mecânico, uma classificação próxima à de máquinas e equipamentos, na província de São Paulo, a partir de 1870, acompanhou o desenvolvimento agrícola da província porque os principais produtos fabricados neste período foram máquinas para processar e beneficiar café e arroz, moinhos de farinha e máquinas para a fabricação de açúcar. Algumas das empresas da indústria metal-mecânica se tornaram, no final do século XIX, grandes fabricantes de máquinas agrícolas, motores a vapor, caldeiras e turbinas, como a Mac Hardy, Lidgerwood e Arens (Suzigan, 2000, p. 249).

Fabio Erber et alii sustentaram que a produção de equipamentos no país teve seu período de formação a partir da segunda metade do século XIX, e que nesse período o setor teve pouca importância para o processo de acumulação, funcionando como uma atividade complementar à economia primário-exportadora. Apesar das diversas fontes de demanda que promoveram o modesto aparecimento da indústria, sua lógica estava atrelada a uma economia primário-exportadora (Erber et alii, 1973, p. 9). 
Nathaniel Leff começou sua análise sobre as origens da indústria de máquinas e equipamentos perguntando como ela pôde ter emergido em uma economia de exportação e como produtores locais poderiam competir com importações em um período sem proteção tarifária e com amplo comércio externo. Depois de argumentar que as principais fontes de demanda para essa indústria estavam relacionadas com a economia de exportação, o autor afirmou que parte da demanda foi atendida por produtores locais por causa de "vantagens locacionais", como os custos de transportes. Entretanto, na maioria das vezes a indústria local foi responsável pelo reparo de máquinas e reposição de peças, complementando as importações (Leff, 1968, p. 9-10).

Luiz Aranha Correa do Lago et alii afirmaram que no início da República havia um clima propício para a produção interna de bens de consumo, dadas as altas tarifas de importação e crescente desvalorização do mil-réis, na década de 1890. Entretanto, a situação da indústria de máquinas não foi tão favorável. A incipiente indústria de máquinas enfrentava isenções de direitos alfandegários sobre vários equipamentos importados, inclusive no principal ramo, máquinas agrícolas, que no início da década de 1890 tinham que pagar uma taxa de expediente de apenas 5\% para a importação. Essas desvantagens aumentaram a concorrência do produtor local em relação às máquinas agrícolas importadas, mas por outro lado, fatores como a desvalorização cambial, elevados custos de transporte dentro do país, facilidades de importação de máquinas, equipamentos e matérias-primas para o setor e condições específicas de demanda possibilitaram o desenvolvimento de novos estabelecimentos na indústria na década de 1890 (Lago et alii, 1979, p. 21).

Uma explicação para o desenvolvimento da indústria paulista na economia primário-exportadora foi elaborada por Wilson Cano e denominada de "complexo cafeeiro capitalista paulista". Para Cano, a atividade principal e predominante, o café, integrava outros componentes, como a agricultura produtora de alimentos e matérias-primas, a atividade industrial, a implantação e desenvolvimento de ferrovias, a expansão do sistema bancário, a atividade do comércio de exportação e importação, as atividades criadoras de infraestrutura e atividades do Estado. A integração com a atividade industrial apresenta-se em três segmentos, com a produção de equipamentos de beneficiamento de café, a indústria de sacarias de juta para a embalagem de café e demais ramos da indústria manufatureira, com destaque para o têxtil (Cano, 1975, p. 9). 
As atividades integrantes do complexo cafeeiro paulista apresentavam efeitos inter-relacionados como redutores de custos de produção, efeitos ampliadores de produtividade, do excedente, diversificadores do investimento e do mercado. Esses efeitos geravam economias de escala, externas e ampliavam o mercado e a acumulação de capital, diversificando o complexo (Cano, 1975, p. 10). Assim, “o capital que anteriormente se podia chamar de 'cafeeiro' vai, por destino, adquirindo outras denominações: 'bancário', 'industrial', 'comercial', etc." (Cano, 1975, p. 68). Ao explicar o complexo cafeeiro paulista, Wilson Cano argumentou que a fabricação de máquinas e implementos agrícolas e especificamente de beneficiamento aumentou a produtividade e diminuiu os custos de produção de café, com economia de trabalho, melhora da qualidade do produto e preço de venda. Dessa forma, a indústria de máquinas "ampliava o excedente do complexo, introduzia nova tecnologia, ao mesmo tempo em que proporcionava novas oportunidades de inversão" (Cano, 1975, p. 62). Cano limitou-se ao exame de três firmas produtoras de máquinas de beneficiamento (Lidgerwood, Mac Hardy e Arens) que detinham $2 \%$ do valor da produção e $2,8 \%$ do emprego industrial do estado de São Paulo em 1907. As indústrias de máquinas e as de sacarias refletem os "efeitos para trás" que o café proporcionou para o início da formação industrial paulista, além dos "efeitos para frente" com a constituição do mercado para bens de consumo (Cano, 1975, p. 63).

Na mesma linha interpretativa, Sérgio Silva mostrou que a burguesia cafeeira exercia múltiplas funções, ou seja, o capital cafeeiro apresentava-se em diversos aspectos como capital agrário, industrial, bancário e comercial (Silva, 1976, p. 60). Dessa forma, os cafeicultores financiavam novas plantações ou modernizavam os equipamentos das plantações (Silva, 1976, p. 59). Esse autor chamou a atenção para a importância da mecanização das operações de beneficiamento para o desenvolvimento da economia do café em São Paulo. A partir de 1870, secadores mecânicos e classificadores a vapor começaram a substituir os aparelhos rudimentares baseados na força animal ou humana da época da escravidão. A produção com máquinas modernas (secadores Taunay-Silva Telles e máquinas de café Lidgerwood) resultaram em aumento da facilidade de venda e preços mais altos para as safras de café (Silva, 1976, p. 54-56). 
Segundo Warren Dean, em períodos de baixo comércio e de preços em queda do café (1892, 1895 e 1902-1906) a indústria acompanhou essa queda. Quando o preço do café estava em alta (1907-1913) o parque industrial cresceu rapidamente. Neste último período, a valorização da moeda nacional estimulou os empresários a reequiparem e expandirem suas fábricas, o que foi feito com o aumento da importação de novas máquinas (Dean, 1976, p. 94).

Suzigan percebeu a mesma tendência geral da indústria metal-mecânica, com desenvolvimento substancial e acelerado nos anos anteriores à Primeira Guerra. Esse crescimento da indústria metal-mecânica foi estimulado pelo crescimento econômico das exportações de café e borracha, ferrovias, equipamentos de portos e desenvolvimento urbano. Houve crescente investimento, medido pela importação de máquinas para o setor, de 1906-1907 em diante, atingindo um pico de importações em 1912-1913; 6,5 vezes superior ao período inicial. Esse pico de importações de máquinas para a indústria metal-mecânica não seria atingido novamente antes do final da década de 1930 (Suzigan, 2000, p. 256).

Lago et alii também confirmaram a crescente importação de equipamentos para a indústria como um todo, reflexo do rápido crescimento do setor industrial no período de 1907-1913. Entretanto, segundo esses autores, no período ocorreu substituição de importações de bens de consumo não duráveis, não havendo indicação de substituição de importações no setor de máquinas e equipamentos. Assim, os autores não confirmaram que o crescimento industrial do período de 1907-1913 foi favorável à substituição de importações de máquinas, apesar de algumas oficinas de imigrantes que se tornaram empresas importantes do setor posteriormente terem sido fundadas no período, entre as quais a Bardella, fundada em 1911 (Lago et alii, 1979, p. 22-24). Para Suzigan, as empresas que foram fundadas antes da Primeira Guerra Mundial produziam máquinas e implementos agrícolas, tais como máquinas para beneficiar café e arroz, moinhos de milho e mandioca, moendas de cana. Apesar da produção de máquinas agrícolas, algumas empresas mais novas, como a Máquinas Agrícolas Nardini e a Cipriano Micheletto começaram a produção de pequenos tornos, mas apenas no período entre guerras (Suzigan, 2000, p. 295). 
Há uma diferença de opinião sobre as características de produção das empresas, tamanho das firmas e importância do capital estrangeiro na indústria de máquinas e equipamentos no período de 1907 a 1913. Para Erber et alii, as empresas de máquinas e equipamentos tinham características artesanais, estabelecimentos pequenos de produção e participação direta do empresário na produção em muitos casos. Como as características da produção nacional eram muito diferentes do setor já implantado em países desenvolvidos, isso contribuiu para o pouco interesse do capital internacional na indústria nacional, pelo menos no período de 1850 a 1930, os primeiros 80 anos de existência da indústria (Erber et alii, 1973, p. 12-13). Lago et alii, entretanto, contestaram a afirmação de que as características das empresas de máquinas e equipamentos em 1907 eram de empresas artesanais. Para esses autores, os dados do Inquérito Industrial de 1907 mostraram que não se deve negligenciar a quantidade de empresas que não podiam ser classificadas como artesanais. Algumas empresas empregavam centenas de operários em um estabelecimento, com o emprego de máquinas não movidas manualmente. Muitos desses estabelecimentos pertenciam a capitalistas brasileiros, mas empreendimentos britânicos e americanos também foram importantes para o desenvolvimento de fundições, principalmente em São Paulo e no Nordeste. Esses empreendimentos foram nacionalizados com a permanência de seus empreendedores no país, como no caso das oficinas de alemães e italianos, mas alguns como a Lidgerwood, para o caso de São Paulo, mantiveram laços externos pelo menos até a primeira década do século XX (Lago et alii, 1979, p. 34-35).

Em relação à tecnologia, há um relativo consenso entre Erber et alii e Lago et alii de que os produtores locais de máquinas e equipamentos concentravam-se entre 1907 e 1913 nas atividades básicas da construção de equipamentos mecânicos, como forjaria, fundição, usinagem e caldeiraria. Apesar das atividades serem em sua maioria de baixa sofisticação tecnológica, a absorção da limitada tecnologia necessária à produção daqueles bens foi feita com a utilização de mão de obra estrangeira especializada, cópia de máquinas e equipamentos importados e alguns empresários nacionais com conhecimento técnico. Em relação aos equipamentos utilizados pelas empresas da indústria mecânica, algumas unidades maiores podiam abastecer-se com máquinas e equipamentos mais simples, mas a maquinaria mais sofisticada tecnologicamente foi importada, principalmente da GrãBretanha e dos Estados Unidos. Assim, parece haver um consenso na 
historiografia econômica de que, antes da Primeira Guerra Mundial, a produção local de máquinas concentrava-se em sua maioria em equipamentos mais simples e foi pequena a concorrência com as máquinas importadas mais sofisticadas (Erber et alii, 1973, p. 11-12; Lago et alii, 1979, p. 34-36).

Depois de analisar a historiografia econômica no período anterior a 1913, o objetivo do restante da seção é avaliar a historiografia sobre os efeitos da Primeira Guerra Mundial na indústria e especificamente sobre a indústria de máquinas e equipamentos no Brasil e no estado de São Paulo. Apesar de vários avanços na historiografia sobre os efeitos da Primeira Guerra na indústria brasileira como um todo (Versiani e Versiani, 1977, p. 138-140; Suzigan, 2000, p. 51-61), não houve avanços equivalentes quanto aos efeitos da guerra sobre a indústria de máquinas e equipamentos.

Dean fez uma análise muito detalhada sobre os efeitos da Primeira Guerra Mundial na industrialização do estado de São Paulo. Seu argumento começou com a descrição das teses de trabalhos anteriores, principalmente de Roberto Simonsen. Do trabalho de Simonsen teriam derivado as interpretações dos efeitos da guerra sobre a indústria nas obras de Caio Prado Jr., Werner Baer, Dorival Teixeira Vieira, Fernando Henrique Cardoso e Nícia Vilela Luz (ver Dean, 1976, p. 96-97). A conclusão de Simonsen em seu trabalho foi que a guerra acelerou o desenvolvimento industrial, dando origem a um impulso adicional que resultou em grande diversificação de novos produtos. Dean mostrou que houve um rápido aumento na produção industrial de São Paulo entre 1907 e 1920, pelos dados censitários do Centro Industrial do Brasil (1907) e Censo Industrial (1920).

Entretanto, Dean questionou se o aumento rápido da produção industrial entre 1907 e 1920 ocorreu durante a guerra, pois o período dos dois Censos incluiu seis anos anteriores (1908-1913) e dois posteriores à guerra (1918-1920). Além das informações serem de períodos mais amplos do que o compreendido pela guerra, Dean apontou que as séries estatísticas sobre as quais os trabalhos clássicos basearam-se possuem defeitos graves que, depois de corrigidos, revelaram um crescimento industrial mais lento. $\mathrm{O}$ autor apontou também que o Censo de 1907 não é um censo propriamente dito, e sim um trabalho realizado por uma organização particular, que não coletou informações de muitas pequenas empresas no interior, 
concentrando-se em levantamento parcial de firmas maiores. Tudo isso contribuiu para a confusão na interpretação dos impactos da Primeira Guerra Mundial sobre a industrialização brasileira e paulista. Os trabalhos clássicos, em sua maioria, ignoraram os problemas das fontes e concluíram que as pequenas e médias empresas de São Paulo começaram sua operação durante a Primeira Guerra, tendo por base a média de operários por firma em 1907 de setenta e nove para em torno de vinte e um operários por firma em 1920, o que seria um equívoco, dado que as informações de 1907 são concentradas em firmas maiores (Dean, 1976, p. 100-101). Dean também criticou os cálculos para o período de guerra, feitos por Simonsen. Os principais problemas foram: a) a utilização de 1914 como ano-base, um ano atípico e de retração, que exagera o ritmo verdadeiro de crescimento industrial; b) a suposição de que os custos dos fabricantes cresceram no mesmo ritmo do que o custo de vida, o que não é confirmado na realidade porque matérias-primas, máquinas e combustíveis utilizados pela indústria custavam quatro vezes mais do que no período antes da guerra, revelando que o custo dos fabricantes subiu mais rápido do que o custo de vida da população; c) os dados de custo de vida para deflação dos valores foram inadequados, porque além de não terem relação com o aumento de preços industriais eram pouco confiáveis (Dean, 1976, p. 102-103).

Assim, ao contrário dos trabalhos clássicos, em especial de Simonsen, que analisaram os impactos da Primeira Guerra Mundial como favoráveis para a industrialização brasileira, Dean afirmou que "a Primeira Guerra Mundial não foi, por si mesma, particularmente estimulante para a indústria paulista" (Dean, 1976, p. 107). E ainda que "poder-se-á até perguntar se a industrialização de São Paulo não se teria processado mais depressa se não tivesse havido guerra" (Dean, 1976, p. 114). Entretanto, apesar do tom pessimista quanto aos efeitos da guerra na industrialização paulista, Dean afirmou que houve algum avanço na produção industrial durante o período, mas com pouquíssimas novas fábricas e com maior utilização da capacidade instalada, "principalmente pelo funcionamento, durante maior número de horas, da maquinaria existente ou pela produção manual" (Dean, 1976, p. 104). Um aspecto importante dos efeitos da guerra sobre o comércio importador foi que as importações de matérias-primas e máquinas e equipamentos tiveram reduções bem maiores do que as de bens de consumo, ou seja, o impacto foi diferente entre as categorias de bens importados, afetando muito pouco a quantidade 
de bens de consumo, principalmente de gêneros alimentícios e afetando muito a quantidade das importações de categorias que continham bens de capital. O declínio da quantidade das importações entre $1909-1913$ e 1914-1918 foi de 73\% para máquinas e de 6\% para produtos alimentícios (Dean, 1976, p. 98-99). O comércio exportador foi afetado apenas quando os Estados Unidos entraram na guerra, sendo que o ano de 1917 assinalou o início da crise. Mas a crise foi amenizada pela diversificação de exportações de produtos pouco essenciais, como o café, para produtos essenciais, principalmente cereais, carne enlatada e produtos têxteis (Dean, 1976, p. 104-105).

Assim, o desafio enfrentado pela indústria na Primeira Guerra foi a manutenção dos equipamentos existentes e da produção e não a expansão dos mercados compradores (Dean, 1976, p. 99). No entanto, a Primeira Guerra afetou positivamente o desenvolvimento industrial na economia paulista em um aspecto: fundação de oficinas metalúrgicas, que tinham como objetivo produzir peças de máquinas e máquinas inteiras para agricultura e indústria, basicamente utilizando o ferro fundido, e o reparo de equipamentos existentes. Essas firmas, geralmente pequenas fundições ou oficinas metalúrgicas, necessitavam de equipamentos simples para operar e a matéria- prima provinha de metal usado retrabalhado. Apesar de a maioria das oficinas ter fechado quando a guerra terminou, nem todas tiveram esse fim e nem todas realizavam apenas conserto de máquinas. Dean citou o exemplo da Companhia Industrial Martins Barros, que de simples seções de reparos ampliou e diversificou suas atividades para descaroçadores e prensas de algodão; e da oficina de elevadores de F. D. Pirie, um imigrante inglês que mais tarde uniu-se a Carlos Villares, quando começaram a fabricar elevadores e outras máquinas em grande escala (Dean, 1976, p. 106-107).

Wilson Cano deu especial atenção ao exame da evolução da indústria paulista no período da Primeira Guerra Mundial. Para ele, houve uma crise pré-guerra em 1913, que com o início da guerra, em 1914, desacelerou o investimento industrial no restante do período da guerra. A produção, ao contrário do investimento, após o período crítico entre 1913 e 1914, retomou altos níveis de crescimento ${ }^{6}$

6 Essa é a mesma interpretação de João Manuel Cardoso de Mello, na qual "a Primeira Guerra Mundial contribuiu para a recuperação da crise industrial de 1913/14 e a posterior expansão da produção, que se fez absorvendo a capacidade produtiva gerada anteriormente" (Mello, 1991, p. 156). Esse autor afirma também que a lucratividade do setor industrial deve ter aumentado de forma considerável no período de guerra. A análise de Cardoso de Mello, no 
(Cano, 1975, p. 147). Apesar disso, a indústria parece não ter sofrido com a falta de equipamentos durante a guerra. Cano critica a afirmação de Dean de que poucas fábricas teriam sido construídas durante a guerra. Ele reafirma parte das críticas feitas por Sérgio Silva (1976) sobre a criação no país de 5.936 novos estabelecimentos entre 1915 e 1919, segundo o recenseamento de 1919, e 323 novas empresas em São Paulo, entre 1915 e 1917 (Cano, 1975, p. 159-160; Silva, 1976, p.101-102).

Cano apresentou as contradições durante a Primeira Guerra em relação à expansão industrial. Essas contradições estão relacionadas ao fato de a restrição ao fluxo de importações ter estimulado a expansão de setores mais simples da produção industrial, já que a restrição afetou diretamente a importação de insumos e bens de capital, impedindo a implantação de setores industriais mais complexos. A retomada das importações, com o fim das restrições após a guerra, teria constituído barreira, em parte, à instalação de indústrias produtoras de equipamentos nos anos 1920, frutificando pouco a experiência das oficinas mecânicas que reparavam e construíam peças e equipamentos simples durante a Primeira Guerra (Cano, 1975, p. 181-182). Cano tem uma posição pessimista sobre a sustentação dos efeitos da Primeira Guerra para a produção da indústria de máquinas e equipamentos.

Suzigan, ao analisar a evolução da indústria metal-mecânica no período da Primeira Guerra, apoiou-se no relato de Hoover, cônsul americano em São Paulo em 1917, afirmando que houve diversificação dos produtos das fábricas e oficinas paulistas, que já produziam "máquinas e peças para fábricas de tecidos, peças de reposição para maquinaria de estrada de ferro e serviço de bondes, máquinas agrícolas leves, moendas de cana, máquinas para beneficiar café, escolhedores de café, máquinas para beneficiar arroz [...]" (Suzigan, 2000, p. 246). Entretanto, o cônsul americano enfatizou a dependência de importações de máquinas mais sofisticadas tecnologicamente e de matérias-primas para o setor. Essa dependência em relação a matérias-primas, segundo Suzigan, deve ter comprometido a expansão do setor durante o período da Primeira Guerra Mundial. Entretanto, outra possibilidade foi a indústria trabalhar com o ferro obtido da sucata, com a construção de fundições nas próprias empresas. Há o exemplo da construção de uma fundição em 1914 pela Companhia

entanto, foi apenas para a indústria em geral, em nenhum momento atentando especificamente para a indústria de máquinas e equipamentos. 
Mecânica de São Paulo, mas com início da produção de aço apenas em 1918 (Suzigan, 2000, p. 257-258). Suzigan notou, utilizando o Anuário Banas de 1962 sobre a indústria de máquinas, que durante a guerra foram fundadas algumas empresas que ainda estavam em operação em 1962: duas novas fábricas para a produção de máquinas agrícolas, uma fábrica para a produção de máquinas para a indústria de bebidas e uma para a produção de elevadores (Suzigan, 2000, p. 295).

Suzigan confirmou o surgimento de oficinas metalúrgicas que desapareceram após a guerra com o reinício das importações e, baseando-se no exemplo de Dean, relatou uma exceção: uma empresa que surgiu no período da guerra e tornou-se importante posteriormente, a Villares. Assim, "é possível que haja outros casos como este, mas não há evidência disponível” (Suzigan, 2000, p. 258). Neste trabalho avançaremos nessa questão.

A análise de Suzigan sobre a indústria metal-mecânica entre 19141918, apesar de mostrar o surgimento de pequenas oficinas metalúrgicas e de algumas fábricas no período, chegou a uma conclusão pessimista dos impactos da Primeira Guerra Mundial sobre essa indústria. Para ele, a dependência de matérias-primas dificultou o crescimento da produção da indústria metal-mecânica no período e "desse modo, quando as importações de ferro e aço caíram continuamente durante a guerra [...], com certeza, a indústria metalmecânica reduziu suas operações" (Suzigan, 2000, p. 257). A análise de Suzigan sobre os investimentos é que "após registrar altos níveis no período imediatamente anterior à guerra, os investimentos na metal-mecânica caíram drasticamente durante o conflito, e só voltaram a tomar impulso a partir da década de 1920" (Suzigan, 2000, p. 298-299). Com relação à produção "durante a guerra, a produção [da indústria metal-mecânica] parece ter sido reduzida até 1918" (Suzigan, 2000, p. 299).

Lago et alii descreveram brevemente o debate dos efeitos da Primeira Guerra Mundial sobre a industrialização do Brasil, mostrando as duas principais correntes: a) a primeira, que sustentou que a interrupção das importações protegeu o mercado interno e possibilitou grande crescimento industrial no período; b) e a segunda, que argumentou sobre a drástica redução nas importações de máquinas e equipamentos, ocorrida durante a Primeira Guerra, levou à maior 
utilização da capacidade instalada existente. Para os autores, os efeitos da queda na importação de equipamentos no período da Primeira Guerra foram diferenciados entre os setores industriais. Dentro da indústria de bens de capital, o gênero que teve menor redução de importações foi o de material elétrico e de comunicações, que era o gênero mais essencial, dado que existia pouca produção interna desses produtos. Por outro lado, a indústria de equipamentos mecânicos foi a que teve maior redução de importações, importando uma média anual entre 1915-1918 de 30\% do valor importado em 1913 (Lago et alii, 1979, p. 40).

Lago et alii afirmaram que houve aumento na capacidade da indústria de máquinas e equipamentos, com o aumento do número de estabelecimentos fundados durante a Primeira Guerra Mundial. Utilizando dados do Censo Industrial de 1920, eles mostraram que o aumento mais expressivo do número de estabelecimentos industriais de máquinas e equipamentos no país em operação em 1920 ocorreu entre 1915-1919 (39 estabelecimentos), acima dos 35 estabelecimentos fundados entre 1910-1914 e dos 16 entre 1905-1909. Outro indicador utilizado pelos autores que mostrou os efeitos positivos sobre a indústria de máquinas e equipamentos no período foi o crescimento da produção brasileira de ferro de quase quatro mil toneladas em 1913, com queda para duas mil toneladas em 1914, passando para quase doze mil toneladas em 1918 (Lago et alii, 1979, p. 37-39).

Apesar da análise favorável de Lago et alii dos efeitos da Primeira Guerra Mundial sobre a indústria de máquinas em termos de número de estabelecimentos, aumento de produtividade, da produção interna, que supriu entre $32,9 \%$ e $35,6 \%$ da oferta global de máquinas em 1919, havia ainda grande dependência brasileira de importação de máquinas em 1919, principalmente das mais sofisticadas tecnologicamente. O principal demandante de equipamentos e máquinas em 1919, o setor agrícola, utilizou implementos em pequena escala: $15 \%$ dos estabelecimentos utilizavam algum instrumento ou máquina para a cultura, dos quais $13,9 \%$ empregavam arados; $7,1 \%$ grades; $1,2 \%$ semeadores; $1,7 \%$ cultivadores; $0,8 \%$ ceifadores e apenas $0,2 \%$ tratores (Lago et alii, 1979, p. 53-54). 
O que efetivamente ocorreu com a produção, investimento e lucratividade da indústria de máquinas e equipamentos em São Paulo no período da Primeira Guerra? Quais as empresas fundadas no período da Primeira Guerra que sobreviveram à retomada do comércio de importação de máquinas e equipamentos e quais as firmas que fecharam? Quais as empresas que se tornaram importantes para a indústria de máquinas e equipamentos no período posterior? Essas são algumas das perguntas que as próximas seções tentarão responder.

\section{As empresas de máquinas e equipamentos no início do século XX}

Nesta seção, apresentaremos as empresas de máquinas e equipamentos no estado de São Paulo no início do século XX. A Tabela 1 apresenta as empresas de máquinas, oficinas mecânicas e fundições em $1907 .^{7}$

7 Infelizmente a principal fonte de dados para o período, o Censo Industrial elaborado em 1907 pelo Centro Industrial do Brasil, não apresenta dados de fundação das empresas. Entretanto, identificamos a data entre parênteses quando possuímos a informação de fundação da empresa. 
Tabela 1 - Empresas de máquinas, oficinas mecânicas e fundições, estado de São Paulo, 1907 (em mil-réis correntes)

\begin{tabular}{|c|c|c|c|c|}
\hline Empresa & Cidade & Operários & Capital & Valor da Produção \\
\hline F. \& L. Sydow (antes 1891) & São Paulo & 21 & 4.000 & 100.000 \\
\hline F. Amaro (1892) & São Paulo & 100 & 200.000 & 700.000 \\
\hline Cia. Mecânica Importadora (1890) & São Paulo & 353 & 5.000 .000 & 303.000 \\
\hline Rizkallah Jorge & São Paulo & 45 & 80.000 & 75.000 \\
\hline Herman Stoltz \& C. & São Paulo & 51 & 100.000 & 100.000 \\
\hline Aliberti \& C. & São Paulo & 33 & 60.000 & 12.000 \\
\hline J. Rangel \& C. & São Paulo & 22 & 20.000 & 144.000 \\
\hline Philadelpho Castro & São Paulo & 15 & 25.000 & 60.000 \\
\hline Affonso Mariano & São Paulo & 95 & 40.000 & 480.000 \\
\hline Antonio Marmano & São Paulo & 65 & 50.000 & 360.000 \\
\hline Huntgen \& C. & São Paulo & 74 & 350.000 & 380.000 \\
\hline Lidgerwood Company Limited (1860) & São Paulo & 206 & 400.000 & 583.000 \\
\hline Bacheli \& Bulgarelli & São Paulo & 5 & 4.000 & 36.000 \\
\hline Cardinali \& Matarazzo & São Paulo & 53 & 50.000 & 160.000 \\
\hline Craig \& Martins (1895) & São Paulo & 105 & 100.000 & 400.000 \\
\hline Craig \& Martins & São Paulo & 76 & 100.000 & 200.000 \\
\hline Bernardo Kuntgen & São Paulo & 136 & 700.000 & 550.000 \\
\hline Caldas \& C. & Piracicaba & 10 & 50.000 & 96.000 \\
\hline Companhia Mac Hardy (1875) & Campinas & 254 & 978.000 & 860.000 \\
\hline Pedro Anderson \& C. & Campinas & 49 & 98.000 & 600.000 \\
\hline Pedro Faber & Campinas & 7 & 40.000 & 30.000 \\
\hline Lidgerwood Company Limited (1860) & Campinas & 46 & 100.000 & 100.000 \\
\hline Arens Irmãos (1876) & Jundiaí & 168 & 650.000 & 920.000 \\
\hline Jefferson Barreto \& C. & São Paulo & 51 & 300.000 & 350.000 \\
\hline A. Milanesi \& Irmãos (1900) & Botucatu & 15 & 30.000 & n.d. \\
\hline Carlos Tonanni (1902) & Jaboticabal & 110 & 600.000 & n.d. \\
\hline Haupt \& Cia. (1823) & São Paulo & 28 & n.d. & n.d. \\
\hline Vagnotti \& Cia. (1900) & São Paulo & 149 & n.d. & n.d. \\
\hline Indústria Mecânica Cavallari (1905) & São Paulo & 107 & n.d. & n.d. \\
\hline J. Nicola \& Irmãos (1888) & Mococa & 57 & n.d. & n.d. \\
\hline Serafim Blasi \& Cia. (1894) & Botucatu & 74 & n.d. & n.d. \\
\hline Antonio Diederichsen (1903) & Ribeirão Preto & 107 & n.d. & n.d. \\
\hline J. Klowza (1903) & Jundiaí & 1 & n.d. & n.d. \\
\hline Carlos Bonfanti (1905) & Leme & 14 & n.d. & n.d. \\
\hline Metalúrgica Ruegger (1895) & Araras & n.d. & n.d. & n.d. \\
\hline Indústria Metal. Bruno Meyer (1892) & Rio Claro & 49 & n.d. & n.d. \\
\hline Naschold \& Cia. Ltda. (1897) & São Paulo & 120 & n.d. & n.d. \\
\hline
\end{tabular}

Fonte: FIBGE. O Brasil: suas riquezas naturais e suas indústrias, 3 vol., 1909. Séries estatísticas retrospectivas. Rio de Janeiro: IBGE, 1986. DEIC/SACOP/SP. Boletim da Diretoria de Indústria e Comércio, 1908-1928. DEE/DEPC/SP. Catálogo das indústrias do estado de São Paulo, município da capital e interior, 1945, São Paulo: Tipografia Brasil, 1947. BANAS, G. Anuário Banas: a indústria de máquinas, São Paulo: Editora Banas, 1962.

Nota: n.d. = não disponível. 
Das 20 empresas das quais conseguimos informações sobre data de fundação e estavam em operação em 1907, 7 foram fundadas antes de 1891 (Frederico Sydow, Cia. Mecânica e Importadora, Lidgerwood, Mac Hardy, Arens, J. Nicola e Haupt) e 13 empresas foram fundadas após 1891, sugerindo um crescimento da indústria entre 1891 e 1907. Das 13 empresas fundadas depois de 1891, 6 aparecem entre 1891 e 1899 (Francisco Amaro, Craig e Naschold, em São Paulo; Ruegger, Mayer e Serafim Blasi, no interior do estado) e 7 entre 1900 e 1907 (Vagnotti e Cavallari, em São Paulo; Milanesi, Tonanni, Diederichsen, Klowza e Bonfanti, no interior do estado).

É interessante notar que a maioria das empresas fundadas entre 1891 e 1907 não teve ligação direta com fazendeiros (como empreendedores), apesar de algumas empresas crescerem com apoio de fazendeiros de café (notadamente a Mac Hardy e Arens). As primeiras empresas foram fundadas geralmente por um imigrante (recém-chegado ou já estabelecido nas cidades) com o objetivo de suprir o mercado local ou regional de máquinas específicas, como reparo e construção de peças para as indústrias têxteis, de papel e borracha e outros bens de consumo, na capital do estado; e de máquinas para o beneficiamento da agricultura local (mandioca, arroz, cana-de-açúcar) e de exportação (café), além de máquinas para a indústria de consumo (como a alimentícia, de massas) no interior do estado.

O que explica o crescimento da indústria de máquinas no período? A demanda oriunda de um mercado local ou regional pode ser mais facilmente suprida por uma empresa instalada na região em que atua, já que ao estar mais próxima conhece as necessidades e características do mercado regional. Muitos ramos necessitavam de máquinas específicas, com características de produção artesanal. Assim, além do incentivo econômico da utilização de matérias-primas locais (madeira, por exemplo) e do custo do transporte, outro incentivo pode ser atribuído à facilidade de reposição de peças e assistência das máquinas, bem como a possibilidade de atender a demanda específica de setores ainda em estágios iniciais. Isso não quer dizer que a sobrevivência e o crescimento dessas empresas foram resultados fáceis. Havia grande concorrência de máquinas estrangeiras, o que exigiu dos empresários criação e adaptação de produtos e processos das empresas às necessidades do mercado. 
É por isso que algumas empresas começaram a produzir máquinas e equipamentos para um ramo específico e posteriormente expandiram suas atividades para outros ramos próximos, como se notará nas próximas seções.

\section{Os efeitos da Primeira Guerra Mundial na indústria de má- quinas e equipamentos paulista}

Nesta seção será examinada a evolução da indústria de máquinas e equipamentos paulista na década de 1910, atentando para os efeitos da Primeira Guerra. O objetivo é trazer luz para a divergência historiográfica sobre os efeitos do conflito na indústria de máquinas e equipamentos, especialmente em São Paulo, com informações originais, não utilizadas pela literatura. A Tabela 2 apresenta informações sobre o capital de novas firmas registradas na indústria de máquinas, oficinas mecânicas e fundições; importação de máquinas; fundação de empresas; o capital médio das empresas fundadas e a porcentagem das importações de máquinas em relação às importações totais entre 1911 e $1920 .^{8}$

Pela análise da Tabela 2 notamos que o capital de novas firmas registradas na indústria de máquinas, oficinas mecânicas e fundições entre 1912 e 1913 caiu quase pela metade (o capital em 1913 representou 47,8\% do apresentado em 1912). Em 1916 há uma recuperação dos níveis do capital das empresas, mas foi apenas em 1919 que o capital de novas firmas da indústria de máquinas, oficinas mecânicas e fundições voltou ao nível de 1912. Nos quatro anos da Primeira Guerra Mundial (1914-1918) o capital registrado das novas firmas foi de 2.564 contos de réis de 1920, praticamente o mesmo valor do que nos dois anos anteriores entre 1912-1913, 2.535 contos de réis de 1920, mesmo com a forte queda no ano de 1913. Assim, os efeitos do conflito mundial foram muitos negativos para a evolução do capital registrado de novas empresas na indústria de máquinas, oficinas mecânicas e fundições no estado de São Paulo. Pela análise das importações de máquinas em termos reais é possível verificar um declínio entre 1913 e 1915. Depois desse ano as importações de

8 Os dados de capital da indústria de máquinas, oficinas mecânicas e fundições foram retirados dos registros nos Contratos da Junta Comercial de São Paulo, anotados mensalmente entre 1911 e 1922, e publicados no Boletim da Diretoria da Indústria e Comércio em 11 volumes. 
máquinas crescem, mas em termos reais ficaram até 1919 abaixo do nível apresentado em 1913 (ver Tabela 2). Assim, o conflito mundial causou forte redução na importação de máquinas em São Paulo, que ainda em 1919 não havia retornado os níveis anteriores ao conflito.

Houve também crescimento do número médio de empresas fundadas entre 1911-1915 (média anual de 7 estabelecimentos) e 19161920 (média anual de 14 estabelecimentos). Essas empresas, no geral, constituíram estabelecimentos bem menores do que os apresentados no início do século XX. Eram pequenas empresas provavelmente com o objetivo de reparo de máquinas e reposição de peças. Isso sugere que a indústria paulista e a de máquinas e equipamentos produziram no período de guerra (principalmente 1915-1918) com maior utilização da capacidade instalada (com máquinas na maioria importadas no período anterior), o que forçou a reposição de peças e a manutenção por pequenas oficinas fundadas no período e também alguma substituição de produtos importados por nacionais.

Tabela 2 - Dados gerais sobre a indústria de máquinas, oficinas mecânicas, fundições e importações de máquinas, estado de São Paulo, 1911-1920 (em mil-réis constantes de 1920 e porcentagem)

\begin{tabular}{cccccc}
\hline Ano & $\begin{array}{c}\text { Capital de novas firmas } \\
\text { de máquinas, oficinas } \\
\text { mecânicas e fundições } \\
\text { (preços de 1920) }\end{array}$ & $\begin{array}{c}\text { Importação de } \\
\text { máquinas (preços } \\
\text { de 1920) }\end{array}$ & $\begin{array}{c}\text { Empresas } \\
\text { fundadas }\end{array}$ & $\begin{array}{c}\text { Capital médio } \\
\text { (preços de 1920) }\end{array}$ & $\begin{array}{c}\text { \% importações } \\
\text { de máquinas das } \\
\text { importações totais }\end{array}$ \\
\hline 1911 & 1.406 .371 & 39.199 .846 & 6 & 234.395 & 12 \\
1912 & 1.666 .337 & 48.793 .910 & 8 & 208.292 & 13 \\
1913 & 869.188 & 49.701 .450 & 8 & 108.648 & 12 \\
1914 & 74.455 & 21.909 .461 & 4 & 18.614 & 10 \\
1915 & 163.754 & 9.457 .152 & 9 & 18.195 & 4 \\
1916 & 769.175 & 12.947 .641 & 11 & 69.925 & 5 \\
1917 & 515.316 & 17.661 .062 & 16 & 32.207 & 6 \\
1918 & 1.043 .095 & 18.183 .260 & 12 & 86.925 & 6 \\
1919 & 1.904 .270 & 31.528 .891 & 23 & 82.794 & 8 \\
1920 & 1.056 .000 & 62.724 .509 & 10 & 105.600 & 10 \\
\hline
\end{tabular}

Fonte: DEIC/SACOP/SP. Boletim da Diretoria de Indústria e Comércio, 1911-1921. REAE/SP. Anuário Estatístico de São Paulo, 1911-1920, São Paulo: Tipografia Espindola \& Comp.

Nota: Os valores foram deflacionados pelo índice setorial de Indústria de HADDAD, 1975, p. 7. Os valores de capital representam o registro de novas firmas

Esse movimento de fundação de pequenas oficinas evidencia que os efeitos da Primeira Guerra Mundial foram favoráveis para a pro- 
dução da indústria de máquinas e equipamentos? Essas empresas conseguiram manter-se no mercado após o fim das condições econômicas formadas pela guerra? Que empresas foram fundadas e quais conseguiram prosperar? Elas continuaram existindo nas décadas seguintes, como nas décadas de 1930 até 1960? Antes de responder essas questões é interessante avaliar o número de empresas presentes e fundadas no período de 1914-1918. Segundo uma publicação do Boletim da Indústria e Comércio, havia no estado de São Paulo $7.681^{9}$ estabelecimentos industriais em 1915, incluindo 769 engenhos de açúcar. Do total de estabelecimentos, 65 eram empresas de máquinas e equipamentos e 62 eram fundições. A Tabela 3 apresenta os números de empresas na indústria de máquinas e fundições por municípios.

Tabela 3 - Oficinas, fábricas de máquinas e fundições, estado de São Paulo, 1915

\begin{tabular}{lccccc}
\hline Município & Máquinas Fundições & $\begin{array}{c}\text { Máquinas e } \\
\text { fundições }\end{array}$ & Total da indústria & $\begin{array}{c}\text { \% máquinas } \\
\text { e fundições }\end{array}$ \\
\hline Amparo & 1 & 0 & 1 & 88 & 1,14 \\
Araraquara & 0 & 1 & 1 & 63 & 1,59 \\
Araras & 0 & 1 & 1 & 101 & 0,99 \\
Bauru & 0 & 1 & 1 & 54 & 1,85 \\
Botucatu & 1 & 3 & 4 & 78 & 5,13 \\
Campinas & 3 & 3 & 6 & 230 & 2,61 \\
Campo Largo de Sorocaba & 0 & 1 & 1 & 13 & 7,69 \\
Capital (São Paulo) & 50 & 31 & 81 & 1.612 & 5,02 \\
Jaboticabal & 1 & 1 & 2 & 181 & 1,10 \\
Jundiaí & 1 & 1 & 2 & 42 & 4,76 \\
Limeira & 0 & 1 & 1 & 118 & 0,85 \\
Mococa & 1 & 1 & 2 & 35 & 5,71 \\
Mogi Mirim & 2 & 0 & 2 & 205 & 0,98 \\
Pirassununga & 0 & 1 & 1 & 115 & 0,87 \\
Ribeirão Preto & 1 & 2 & 3 & 89 & 3,37 \\
Rio Claro & 0 & 1 & 1 & 102 & 0,98 \\
Santa Barbara & 4 & 1 & 5 & 41 & 12,20 \\
Santos & 0 & 4 & 4 & 86 & 4,65 \\
São Carlos & 0 & 1 & 1 & 74 & 1,35 \\
São Bernardo & 0 & 2 & 2 & 94 & 2,13 \\
São José dos Campos & 0 & 1 & 1 & 11 & 9,09 \\
São Simão & 0 & 1 & 1 & 71 & 1,41 \\
Serra Negra & 0 & 1 & 1 & 33 & 3,03 \\
Sorocaba & 0 & 2 & 2 & 80 & 2,50 \\
Totais & 65 & 62 & 127 & 3.616 & 3,51 \\
\hline & & & & &
\end{tabular}

Fonte: DEIC/SACOP/SP. Boletim da Diretoria de Indústria e Comércio, 1916, p. 208-217.

Nota: As "máquinas" e "fundições" foram agregadas porque muitas empresas que produziam máquinas e equipamentos no período eram classificadas como fundições.

9 A diferença entre o valor total da indústria na Tabela 3 (3.616) e o valor apresentado no texto (7.681) é explicada porque na Tabela 3 aparecem apenas os municípios onde havia registro de oficinas, fábricas de máquinas e fundições. 
A primeira observação sobre a Tabela 3 é a concentração de empresas da indústria de máquinas e fundições na capital paulista $(76,9 \%$ no ramo de máquinas e 50\% no ramo de fundições) em 1915. Outra observação é a concentração de empresas de máquinas e fundições em relação à indústria total em algumas cidades, em que Santa Bárbara é o principal exemplo.

Se considerarmos apenas como indústria mecânica as "oficinas e fábricas de máquinas", o que não é totalmente correto porque muitas das empresas que foram classificadas como "fundições" também produziam máquinas, totalizamos 65 estabelecimentos produtores de máquinas e equipamentos em 1915, no estado de São Paulo (sem contar as 18 oficinas de estrada de ferro espalhadas pelo estado). Comparando esses dados com o Censo Industrial de 1920, encontramos nesse ano, classificadas como subsetores da metalurgia no estado de São Paulo, 35 fundições e laminações de ferro, construção de máquinas em geral e 11 oficinas mecânicas e fabricação de peças acessórias, totalizando 46 estabelecimentos que poderiam ser incluídos na indústria mecânica (DGE/ MAIC, 1927, p. 467). ${ }^{10}$ Portanto, pode ter havido redução no número de estabelecimentos na indústria de máquinas e equipamentos no estado de São Paulo de 65 estabelecimentos em 1915 (considerando apenas as fábricas e oficinas de máquinas) para 46 (considerando as fundições e laminações de ferro, construção de máquinas em geral e as oficinas mecânicas e fabricação de peças acessórias) em $1920 .^{11}$

Das 54 empresas (ver Tabela 4) ${ }^{12}$ que puderam ser classificadas na indústria de máquinas, oficinas mecânicas e fundições em 1919, com dados de várias fontes, inclusive uma Estatística Industrial para o interior do estado de São Paulo 1918-1919, ${ }^{13}$ conseguimos informações de que 11 foram fundadas no período da Primeira Guerra Mundial (1914-1918): F. Amaro \& Comp., fundada em 1918, M. Porto \& Garcia, fundada em 1917 e encerrada em 1920, R. N. Duncan, fundada em 1917 e encerrada em 1921, todas em Santos; Puccetti \& Cia., fundada em 1915, Mario Babbini, fundada em 1916, Henrique

${ }^{10}$ Infelizmente o Censo Industrial de 1920 não separa as fundições das empresas produtoras de máquinas.

${ }^{11}$ A redução no número de empresas pode ser explicada por problemas de cobertura de pesquisas do Censo de 1920, que tende a ter levantado empresas maiores.

${ }^{12}$ Um valor próximo ao registrado pelo Censo Industrial de 1920 para o estado de São Paulo: 35 fundições e laminação de ferro e construção de máquinas e 11 oficinas mecânicas, fabricação de peças: total de 46 empresas (DGE/ MAIC, 1927, p. 467).

13 A Estatística não foi analisada pela historiografia econômica e, portanto, é inédita. 
Grassmann Filho, em 1917, Lilla \& Irmãos, em 1918, Fundição Progresso, em 1917, L. Silva, em 1918, Lowsby \& Pirie, depois Pirie \& Villares, em 1918 todas na cidade de São Paulo e a firma Souza, Penteado, depois B. Penteado, em 1916, na cidade de Limeira. Muitas das empresas fundadas entre 1914 e 1919 não sobreviveram até o final de 1919, outras certamente mudaram de ramo de atuação. A Tabela 4 apresenta as empresas de máquinas e equipamentos e fundições em 1919.

Tabela 4 - Empresas de máquinas, oficinas mecânicas e fundições, estado de São Paulo, 1919

\begin{tabular}{|c|c|c|c|c|}
\hline Empresa & Cidade & Capital (em mil-réis) & Operários & Produtos \\
\hline J. Nicola \& Irmãos (1888) & Mococa & 40.000 & 56 & máquinas e turbinas* \\
\hline F. Amaro \& Comp. (1918) & Santos & 100.000 & 40 & máquinas e peças* \\
\hline M. Porto \& Garcia (1917) & Santos & 20.000 & 20 & máquinas e peças* \\
\hline R. N. Duncan (1917) & Santos & 70.000 & 40 & máquinas e peças* \\
\hline Cia. Constr. de Santos S.A. & Santos & 1.000 .000 & 200 & fundição de peças \\
\hline Fortunato Frentoni \& Filhos & Amparo & 30.000 & 20 & oficina mecânica \\
\hline José Ricardo \& Cia. (1919) & Amparo & 16.000 & 5 & oficina mecânica \\
\hline A. Martins & Piracicaba & 4.000 & 1 & fábrica de arados ${ }^{*}$ \\
\hline Luiz Gozola & Itu & 15.000 & 8 & fundição \\
\hline Serafim Blasi (1894) & Botucatu & 150.000 & 22 & máquinas diversas* \\
\hline A. Milanesi \& Irmãos (1900) & Botucatu & 30.000 & 15 & fundições diversas \\
\hline Cia. Lidgerwood (1860) & Campinas & 2.500 .000 & 47 & máquinas diversas* \\
\hline Cia. Mac-Hardy (1875) & Campinas & 980.000 & 200 & máquinas diversas* \\
\hline Alexandre Sim & Campinas & 33.000 & 20 & oficina mecânica \\
\hline Francisco Tadini & Campinas & 2.000 & 2 & oficina de caldeiras \\
\hline A. Ramasco \& Cia. (1914) & Campinas & 15.000 & 18 & Fundição \\
\hline S. Anonyma Arens (1876) & Jundiai & 100.000 & 120 & oficina mecânica* \\
\hline Klouza \& Irmão (1903) & Jundiai & n.d. & 10 & oficina mecânica \\
\hline Carlos Tonanni (1902) & Jaboticabal & 600.000 & 110 & máquinas diversas* \\
\hline C. Martins \& Cia. & Araraquara & 100.000 & 40 & oficina de fundição \\
\hline Emilio Spardan \& Cia. & Limeira & 15.000 & 2 & oficina mecânica \\
\hline Nobre \& Ignolf & Orlandia & 9.000 & 10 & oficina mecânica \\
\hline Otto G. Grassmann & São Simão & 5.000 & 10 & oficina mecânica \\
\hline Vicente Serpentino & Descalvado & 40.000 & 6 & oficina mecânica \\
\hline Angelo Fodescari \& Filho & Descalvado & 18.000 & 5 & oficina mecânica \\
\hline Eleuterio Rela & Itatiba & 30.000 & 3 & oficina mecânica \\
\hline Gomes \& Irmão & Bocaina & 5.000 & 6 & oficina mecânica \\
\hline Belisario \& Beck & Palmeiras & 1.500 & 3 & oficina mecânica \\
\hline Coseth \& Filho & Pirassununga & 35.000 & 10 & oficina mecânica \\
\hline Luiz Bosithião & Pirassununga & 20.000 & 3 & oficina mecânica \\
\hline Fredem Jeranaio \& Filhos & E. Santo Pinhal & 30.000 & 8 & máquinas diversas ${ }^{\star}$ \\
\hline Pedro Scarpini & Bragança & 12.500 & 3 & oficina mecânica \\
\hline Adolpho Bianchi \& Irmão & Ribeirão Preto & 27.000 & 20 & oficina mecânica \\
\hline Antonio Diederichsen (1903) & Ribeirão Preto & 200.000 & 100 & oficina mecânica \\
\hline B. Penteado (1916) & Limeira & 100.000 & 60 & máquinas beneficiar* \\
\hline Martins Barros (1911-16) & São Paulo & 2.000 .000 & 200 & máquinas lavoura e indústria* \\
\hline
\end{tabular}


Tabela 4 - Empresas de máquinas, oficinas mecânicas e fundições, estado de São Paulo, 1919 (Continuação)

\begin{tabular}{|c|c|c|c|c|}
\hline Empresa & Cidade & Capital (em mil-réis) & Operários & Produtos \\
\hline Mario Babbini \& Irmão (1916) & São Paulo & 200.000 & 95 & máquinas lavoura e indústria* \\
\hline Pirie \& Villares (1918) & São Paulo & n.d. & n.d. & oficina mecânica* \\
\hline L. Silva \& Cia. Ltda. (1918) & São Paulo & 400.000 & 4 & Instrumentos agrícolas ${ }^{\star}$ \\
\hline Oficina Craig Ltda. (1896) & São Paulo & 675.931 & 117 & máquinas diversas* \\
\hline Vagnotti \& Cia. (1900) & São Paulo & 4.613 .015 & 149 & $\begin{array}{c}\text { acessórios para máquinas } \\
\text { têxteis* }\end{array}$ \\
\hline Ind. Mecânica Cavallari (1905) & São Paulo & 1.055 .431 & 107 & $\begin{array}{c}\text { máquinas para papel e } \\
\text { borracha* }\end{array}$ \\
\hline José Dapice (1910) & São Paulo & 28.000 & & máquinas tecidos* \\
\hline Haupt \& Cia. (1823) & São Paulo & 371.942 & 28 & bombas hidráulicas \\
\hline $\begin{array}{l}\text { Bardella Ind. Mecânicas } \\
\text { (1911) }\end{array}$ & São Paulo & 9.318 .908 & 182 & eixos e fundições de peças* \\
\hline Puccetti \& Cia. (1915) & São Paulo & 266.642 & 18 & máquinas para bebidas* \\
\hline Henrique Grassmann F.(1917) & São Paulo & 11.000 & 1 & foices, arados, consertos \\
\hline Lilla \& Irmãos (1918) & São Paulo & 285.842 & 30 & torrador e máquinas* \\
\hline Carlos Bonfanti (1905) & Leme & 230.800 & 14 & máquinas diversas* \\
\hline Metalúrgica Ruegger (1895) & Araras & n.d. & n.d. & n.d. ${ }^{*}$ \\
\hline Ind.Metal.Bruno Meyer (1892) & Rio Claro & n.d. & 49 & n.d. ${ }^{*}$ \\
\hline Naschold (1897) & São Paulo & n.d. & 120 & n.d. \\
\hline Fundição Progresso (1917) & São Paulo & n.d. & 450 & n.d. \\
\hline Cia. Mecân. Importadora(1890) & São Paulo & 10.000 .000 & n.d. & n.d. ${ }^{*}$ \\
\hline
\end{tabular}

Fonte: DEIC/SACOP/SP. Boletim da Diretoria de Indústria e Comércio, Estatística Industrial (vários anos). DEIC/SAIC/SP. Estatística Industrial do Estado de São Paulo, 1929. DEE/DEPC/ SP. Catálogo das indústrias do estado de São Paulo, município da capital e interior, 1945, São Paulo: Tipografia Brasil, 1947. BANAS, G. Anuário Banas: a indústria de máquinas, São Paulo: Editora Banas, 1962. SÃ́ PAULO. Diário Oficial do Estado de São Paulo, 1919.

Nota: * Empresas comprovadamente produtoras de máquinas em 1919; n.d.= não disponível.

As condições econômicas criadas pela Primeira Guerra Mundial, com redução nas compras de máquinas importadas do exterior, foram favoráveis para a fundação de empresas para reparo e reposição de peças de máquinas, geralmente pequenas empresas. Apesar da grande quantidade de máquinas importadas no período anterior, é coerente pensar que no período do conflito houve aumento de demanda por máquinas e equipamentos, revelado pelo aumento de fundação de novas empresas. Assim, apesar de não haver dados sobre a produção agregada de máquinas e equipamentos locais, é razoável afirmar que houve aumento da produção pelas empresas fundadas antes do conflito, com aumento da utilização de sua capacidade, e por novas oficinas. 
Assim, não parece totalmente correta a afirmação de Suzigan de que "durante a guerra não houve nenhum desenvolvimento significativo na produção interna de insumos básicos [...] ou na produção de bens de capital" (Suzigan, 2000, p. 59). O autor tirou essas conclusões afirmando que a queda das importações de ferro e aço durante a guerra restringiu o crescimento da produção da indústria. Parece certo que a queda da importação de máquinas diminuiu o investimento total na indústria, inclusive na indústria metal-mecânica, como corretamente apontou Suzigan. Entretanto, parte da matéria-prima utilizada na indústria de máquinas no período, principalmente nas máquinas para a agricultura, pode ter sido a madeira. Com relação à produção da indústria de máquinas e equipamentos em São Paulo, parece mais correta a afirmação de que o período de 1915 a 1919 foi favorável "à produção interna de equipamentos mais simples, enquanto perdurava a importação, já a níveis bem inferiores, dos equipamentos mais sofisticados não produzidos internamente" (Lago et alii, 1979, p. 40). A evolução da indústria de máquinas e equipamentos paulista durante a Primeira Guerra pode ser melhor entendida seguindo as contribuições de Albert Fishlow (1972) para a indústria brasileira e Flávio Versiani e Maria Teresa Versiani (1977) para a indústria têxtil brasileira.

Para Fishlow (1972) no período da Primeira Guerra "houve uma influência favorável sobre a produção [da indústria brasileira], que não pode ser negada [...] De maior importância imediata para os proprietários das fábricas foram os lucros decorrentes do grande aumento dos preços [...] Grandes lucros em 1916 e 1917 foram uma consequência, acumulação de reservas para posterior compra de equipamento de capital foi outra" (Fishlow, 1972, p. 19). Assim, Fishlow (1972) deu ênfase para a importância da lucratividade dos produtores internos no período de guerra, que refletiu nos grandes investimentos pós-guerra. Essa perspectiva parece correta também para a indústria de máquinas e equipamentos paulista, que devido ao aumento da demanda interna com a queda da importação, aumentou a produção interna com maior utilização da capacidade (das empresas fundadas antes do conflito) e novas oficinas, com maior lucratividade, como veremos em um exemplo na próxima seção. 
Versiani e Versiani (1977) argumentaram que a Primeira Guerra pode ter sido a salvação para muitos produtores da indústria têxtil, já que o período imediatamente anterior foi de crise. No período anterior ao conflito, o investimento na indústria têxtil cresceu aparentemente em uma fase de crise de demanda. A explicação dos autores é que as novas instalações produtivas são mais eficientes e a crise revelou-se para os produtores menos eficientes. Isso ocorreu porque a evolução do progresso técnico na produção de tecidos não alterou a qualidade do produto, sendo que a variação entre tecidos produzidos com equipamentos de diferentes gerações foi o seu custo de produção.

A possibilidade de produzir mais barato é o diferencial de um produtor que possua um equipamento mais novo e tecnologicamente superior. Entretanto, "a indiferenciação de seu produto com relação ao fabricado com instalações comparativamente obsoletas poderá fazer com que, numa situação favorável de procura, ambos possam ser produzidos e vendidos compensadoramente." (Versiani e Versiani, 1977, p. 139). Assim, as condições da Primeira Guerra que resultaram em diminuição das importações criaram as condições favoráveis de procura para firmas com equipamentos novos e antigos. Com o fim do conflito e a volta de uma conjuntura competitiva, apenas as firmas mais eficientes permaneceram na produção (Versiani e Versiani, 1977, p. 139).

A evolução da indústria de máquinas e equipamentos paulista parece ter semelhança com indústria têxtil no período. Apesar do crescimento do número de empresas, algumas que surgiram no período da Primeira Guerra não conseguiram crescer e desenvolver posteriormente, resultando, portanto, que os efeitos da Primeira Guerra Mundial para a indústria de máquinas e equipamentos paulista foram favoráveis no curto prazo. Entretanto, nem todos os efeitos da Primeira Guerra Mundial sobre a entrada de empresas na indústria de máquinas e equipamentos paulista foram de curto prazo. Houve casos de sucesso de empresas fundadas no período de 1914-1918, que se tornaram eficientes no pós-guerra. Das onze empresas fundadas entre 1914 e 1918 que operavam na indústria de máquinas, oficinas mecânicas e fundições em 1919 (Tabela 4), sete (B. Penteado, Mario Babbini, Pirie \& Villares, L. Silva, Puccetti, Lilla \& Irmãos e Fundição Progresso) cresceram e se desenvolveram ao longo das 
décadas de 1920 e 1930, sendo que algumas aparecem operando nos anos 1960.

A questão da lucratividade e financiamento da maior firma da indústria de máquinas e equipamentos ao longo da década de 1910 é o tema da próxima seção.

\section{A rentabilidade e o financiamento em uma sociedade anônima: o caso da Cia. Mecânica Importadora de São Paulo}

O exemplo de maior crescimento de uma empresa na indústria de máquinas e equipamentos durante a década de 1910 foi o da Companhia Mecânica e Importadora de São Paulo. A empresa já era a maior do setor em 1907, em termos de capital social (ver Tabela 1). Durante a década de 1910, inclusive no período da Primeira Guerra Mundial, os indicadores econômicos da empresa foram muito positivos. Com o objetivo de verificar o desempenho dessa empresa, a Tabela 5 apresenta os dados e alguns indicadores do seu balanço patrimonial entre 1910-1920. 
Tabela 5 - Balanços Patrimoniais da Companhia Mecânica Importadora de São Paulo, 1910, 1912, 1914, 1916, 1918, 1920 (em contos de réis correntes)

\begin{tabular}{|c|c|c|c|c|c|c|}
\hline & 1910 & 1912 & 1914 & 1916 & 1918 & 1920 \\
\hline Ativo Circulante & 4.403 & 9.101 & 9.561 & 10.899 & 15.692 & 23.099 \\
\hline Caixa & 39 & 35 & 214 & 343 & 286 & 377 \\
\hline Contas Correntes & 2.241 & 3.155 & 2.704 & 2.473 & 8.895 & 6.384 \\
\hline Mercadorias em Consignação & & & 161 & & 119 & \\
\hline Fazendas Geraes (Estoques) & 1.424 & 4.132 & 2.692 & 4.492 & 3.390 & 8.428 \\
\hline Clientes (Letras a receber) & 309 & 922 & 1.109 & 998 & 394 & 1.502 \\
\hline Títulos caucionados e depósitos & 81 & 85 & 1.599 & 1.795 & 155 & 145 \\
\hline Fabricação (estoque de mat. primas) & 309 & 772 & 1.082 & 798 & 2.453 & 6.263 \\
\hline Ativo Permanente & 3.842 & 4.691 & 6.517 & 7.661 & 15.615 & 23.512 \\
\hline Propriedades, Maquinário, etc. & 2.969 & 3.565 & 4.392 & 5.492 & 11.682 & 16.791 \\
\hline Mobílias e Semoventes & 24 & 80 & 51 & 30 & 1 & 1 \\
\hline Hipotecas & & & 1.501 & 1.537 & 308 & 60 \\
\hline Ações e Títulos & 624 & 689 & 475 & 451 & 3.469 & 6.329 \\
\hline Diversas Contas & 225 & 357 & 98 & 151 & 155 & 331 \\
\hline Ativo Total & 8.245 & 13.792 & 16.078 & 18.560 & 31.307 & 46.611 \\
\hline Passivo Circulante & 1.169 & 5.391 & 7.165 & 6.836 & 5.239 & 16.980 \\
\hline Fornecedores (Contas Gerais) & 559 & 3.258 & 3.537 & 2.322 & 2.858 & 12.249 \\
\hline Letras a Pagar & & & 1.323 & 1.829 & 1.635 & 3.182 \\
\hline Contas a Pagar & 254 & 1.283 & 98 & 121 & 46 & \\
\hline Diversas Contas & 10 & 308 & 88 & 109 & 111 & 462 \\
\hline Consignações Diversas (Gratificações) & & 148 & 161 & 347 & 119 & \\
\hline Garantias Diversas (Val. Depositados) & 82 & 85 & 1.599 & 1.793 & 155 & 145 \\
\hline Dividendos & 253 & 302 & 350 & 300 & 300 & 907 \\
\hline Imposto sobre Dividendos & 11 & 8 & 9 & 15 & 15 & 35 \\
\hline Patrimônio Líquido & 7.090 & 8.404 & 8.916 & 11.724 & 26.070 & 29.631 \\
\hline Capital & 5.000 & 5.000 & 5.000 & 5.000 & 10.000 & 10.000 \\
\hline Fundo de Reserva & 2.069 & 2.518 & 2.795 & 3.493 & 5.977 & 7.208 \\
\hline Lucros que passam para próximo ano & 21 & 886 & 1.121 & 3.231 & 10.093 & 12.423 \\
\hline Passivo Total & 8.259 & 13.795 & 16.081 & 18.560 & 31.309 & 46.611 \\
\hline \multicolumn{7}{|l|}{ Indicadores financeiros } \\
\hline Liquidez Corrente & 3,766 & 1,688 & 1,334 & 1,594 & 2,995 & 1,360 \\
\hline Liquidez Seca & 2,548 & 0,922 & 0,959 & 0,937 & 2,348 & 0,864 \\
\hline Liquidez Imediata & 1,950 & 0,592 & 0,407 & 0,412 & 1,752 & 0,398 \\
\hline Imobilização do Capital & 0,542 & 0,558 & 0,731 & 0,653 & 0,599 & 0,793 \\
\hline Quociente Cobertura Total & 7,053 & 2,558 & 2,244 & 2,715 & 5,976 & 2,745 \\
\hline Estrutura Capital: Participação Capital de Terceiros & 0,165 & 0,641 & 0,804 & 0,583 & 0,201 & 0,573 \\
\hline Quociente Rentabilidade Patrimônio Líquido & 0,003 & 0,105 & 0,126 & 0,276 & 0,387 & 0,419 \\
\hline Quociente Rentabilidade do Ativo & 0,003 & 0,064 & 0,070 & 0,174 & 0,322 & 0,267 \\
\hline$\%$ Capital de Terceiros no Ativo Total & 14,18 & 39,09 & 44,56 & 36,83 & 16,73 & 36,43 \\
\hline \% Capital Próprio no Ativo Total & 85,99 & 60,93 & 55,45 & 63,17 & 83,27 & 63,57 \\
\hline
\end{tabular}

Fonte: SÃO PAULO. Diário Oficial do Estado de São Paulo, 19/03/1911, p. 1202; 25/03/1913, p. 1342; 23/03/1915, p. 1266; 21/03/1917, p. 1412; 27/03/1919, p. 2107; 21/03/1921, p. 2010.

Nota: Os dados foram extraídos dos Balanços Patrimoniais publicados no Diário Oficial do Estado de São Paulo e agregados em "Ativo Circulante", "Ativo Permanente", "Ativo Total", "Passivo Circulante", "Patrimônio Líquido" e "Passivo Total" pelo autor. Os índices foram elaborados pelo autor. A diferença entre Ativo Total e Passivo total em alguns anos é devido ao arredondamento dos dados. 
Comparando os dados do balanço patrimonial, notamos que o valor do ativo real administrado pela Companhia Mecânica Importadora de São Paulo mais do que triplicou entre 1910 e $1920 .{ }^{14}$ Esse crescimento do ativo deu-se com recursos de terceiros de curto prazo (aumento do passivo circulante) até os anos iniciais da Primeira Guerra Mundial (entre 1914-1915), passando o indicador de porcentagem de capital de terceiros no ativo total de $14,2 \%$ em 1910 para $44,6 \%$ em 1914 (ver Tabela 5).

Dos anos iniciais do conflito mundial até 1918, o crescimento da empresa foi financiado com recursos próprios (aumento do patrimônio líquido), passando o indicador de porcentagem de capital próprio de 55,4\% em 1914 para 83,3\% em 1918. Esse aumento de recursos próprios em relação ao ativo total ocorreu devido ao aumento dos lucros acumulados pela empresa, que se refletiu no aumento nos indicadores de rentabilidade sobre o patrimônio líquido (lucros que passam para o próximo ano dividido pelo patrimônio líquido) de 12,6\% em 1914 para 38,7\% em 1918 e rentabilidade do ativo (lucros que passam para o próximo ano dividido pelo ativo total) de 7\% em 1914 para 32,2\% em 1918. Assim, a lucratividade da Companhia Mecânica Importadora aumentou acentuadamente durante a Primeira Guerra Mundial, melhorando os indicadores de rentabilidade entre 1914 e 1918. Foi o aumento do lucro que financiou o desenvolvimento e expansão das operações da empresa nesses anos. A análise do indicador da estrutura de capital (passivo circulante dividido pelo patrimônio líquido) reforça o exposto acima. Em 1914, para cada unidade monetária investida por capital próprio, havia 0,8 unidades monetárias de capital de terceiros. Em 1918, para cada unidade monetária dos sócios, havia 0,2 unidades monetárias de capital de terceiros.

O quociente de imobilização indica a proporção do capital (patrimônio líquido) imobilizado em ativo fixo (ativo permanente). Houve crescimento da imobilização do capital entre 1910 e 1914 (passando de $54,2 \%$ do patrimônio líquido aplicado em ativo permanente em 1910 para 73,1\% em 1914). O quociente de imobilização declinou até 1918, chegando nesse ano em 59,9\% do patrimônio líquido aplicado em ativo fixo.

14 Esse resultado foi obtido da seguinte forma: os dados a preços correntes da Tabela 5 foram deflacionados pelo índice setorial de produto da indústria de Haddad (1975). O valor do ativo de 1910, 8.245 contos a preços correntes, foi transformado a preços constante de 1920, utilizando o índice de $1910=18,8$ e $1920=34,2$. O valor do ativo de 1910 a preços constantes de 1920 é de 14.999 contos, três vezes menor do que o valor do ativo de 1920 de 46.611 contos. 
O quociente de cobertura total (ativo permanente mais ativo circulante, dividido pelo passivo circulante) indica a possibilidade de a empresa cumprir seus compromissos financeiros. A possibilidade de a empresa realizar seus pagamentos permaneceu boa, apesar de queda do quociente de 1910 a 1916. Em 1916, por exemplo, para cada unidade monetária de dívida, havia 2,7 unidades monetárias de ativo real para pagamentos. Os índices de liquidez corrente (ativo circulante dividido pelo passivo circulante), liquidez seca (ativo circulante menos estoques dividido pelo passivo circulante) e liquidez imediata (disponível dividido pelo passivo circulante) da Companhia Mecânica Importadora revelam deterioração financeira em 1914 com relação aos anos anteriores. Em 1910, como revelado pelo índice de liquidez corrente, para cada unidade monetária de dívida de curto prazo, a empresa possuía 3,7 unidades monetárias em disponibilidade ou realizáveis no curto prazo. Esse indicador caiu para 1,3 em 1914, uma situação menos confortável, mas sem risco de insolvência, como revelado pelo índice de cobertura total. Entretanto, de 1914 até 1918, o indicador de liquidez corrente melhorou, chegando a 2,9 neste último ano. $\mathrm{O}$ índice de liquidez seca seguiu praticamente a mesma tendência da liquidez corrente. A diferença entre o índice de liquidez corrente e a seca é não considerar neste último os estoques de mercadorias. Mesmo um índice de liquidez seca abaixo de 1 pode ser considerado normal. A liquidez imediata mede a quantidade de recursos disponíveis, em termos de dinheiro (no caixa) e em contas correntes, para pagar o passivo circulante. Aqui, a análise ficou prejudicada porque não sabemos o montante do passivo circulante da empresa que se destina ao pagamento imediato. Entretanto, mesmo um indicador de liquidez imediata de 0,4, como o apresentado em 1914, pode ser considerado normal.

Assim, apesar da piora em alguns indicadores de liquidez da Companhia Mecânica e Importadora de São Paulo durante a década de 1910, que não deixaram a empresa em situação de risco de insolvência, praticamente todos os outros indicadores econômicos e financeiros melhoram ao longo da década, mesmo nos anos do conflito da Primeira Guerra Mundial. A rentabilidade sobre o patrimônio líquido aumentou mais de três vezes entre 1914 e 1918. O crescimento e expansão das atividades da empresa foram financiados com aumento dos recursos próprios entre os anos inicias ao conflito mundial (1914-1915) até pelo menos o ano de 1918. A empresa soube aproveitar as condições proporcionadas pelos efeitos da Primeira 
Guerra Mundial, principalmente o aumento da demanda devido às menores importações de máquinas e equipamentos do exterior e com possibilidades de diversificação em outros setores.

\section{Conclusões}

Ao longo do trabalho buscou-se traçar um panorama da evolução da indústria de máquinas e equipamentos no estado e São Paulo entre 1900 e 1920. Foi realizado um trabalho de organização e sistematização de dados de várias fontes, para lançar luz sobre a divergência da historiografia econômica em relação a um setor específico da indústria no início do século XX.

O trabalho mostrou que os efeitos da Primeira Guerra Mundial foram muito negativos para a evolução do capital registrado na Junta Comercial por novas firmas na indústria de máquinas, oficinas mecânicas e fundições paulista. No período do conflito diminuiu a importação de máquinas em São Paulo (inclusive para a própria indústria de máquinas e equipamentos), que ainda em 1920 não havia retornado a patamares anteriores a 1914. Como afirmou Suzigan (2000) "após registrar altos níveis no período imediatamente anterior à guerra, os investimentos na metal-mecânica caíram drasticamente nos anos do conflito e só voltaram a tomar impulso a partir da década de 1920" (Suzigan, 2000, p. 299). Assim, concordamos que os efeitos da Primeira Guerra foram negativos para o investimento agregado da indústria de máquinas e equipamentos em São Paulo.

A evolução da produção na indústria de máquinas e equipamentos paulista merece uma qualificação. Há divergência na historiografia econômica que atentou para essa indústria. Warren Dean (1976) e Luiz Aranha Correa do Lago et alii (1979) afirmaram que o período da Primeira Guerra Mundial foi favorável, enquanto Wilson Suzigan (2000) afirmou que foi desfavorável para a produção da indústria de máquinas e equipamentos, conforme vimos na introdução e na segunda seção. Embora não haja dados sobre a produção agregada de máquinas e equipamentos locais no período, nossos resultados indicam ser razoável afirmar que houve aumento da produção pelas empresas fundadas antes do conflito com aumento da utilização de sua capacidade (a exemplo da Cia. Mecânica Importadora de São Paulo) e por 
novas pequenas empresas fundadas no período de guerra. Apesar da grande quantidade de máquinas importadas no período anterior à guerra, é coerente pensar que no período do conflito houve aumento de demanda interna por máquinas e equipamentos, revelada pelo aumento de fundação de novas empresas e grande queda das importações de máquinas. Assim, concordamos com Dean (1976) e Lago et alii (1979) que a evolução da produção da indústria de máquinas e equipamentos foi positiva no período da Primeira Guerra Mundial.

A evolução da produção e lucratividade na indústria de máquinas e equipamentos paulista durante a Primeira Guerra pode ser melhor entendida seguindo as contribuições de Albert Fishlow (1972) para a indústria brasileira e Flávio Versiani e Maria Teresa Versiani (1977) para a indústria têxtil brasileira. Os efeitos da Primeira Guerra que resultaram em diminuição das importações criaram as condições favoráveis de procura e lucratividade tanto para firmas maiores como para pequenas oficinas. Com o fim do conflito e a volta de uma conjuntura competitiva, apenas as firmas mais eficientes permaneceram na produção dessa indústria.

\section{Referências}

\section{Fontes Primárias}

BANAS, G. Anuário Banas: a indústria de máquinas, São Paulo: Editora Banas, 1962.

DEE/DEPC/SP. Catálogo das indústrias do estado de São Paulo: município da capital e interior, 1945 , São Paulo: Tipografia Brasil, 1947.

DEIC/SACOP/SP. Boletim da Diretoria de Indústria e Comércio, 1908-1928, 18 volumes.

DEIC/SAIC/SP. Estatística Industrial do Estado de São Paulo, 1928-1937, 1938-1939.

DGE/ MAIC. Recenseamento do Brasil 1920, vol. V. (primeira parte): indústria, Rio de Janeiro. Tipografia de Estatística, 1927.

FIBGE. Censos Industrial, Comercial e de Serviços. (série regional), vol. XXV, tomo, estado de São Paulo, Rio de Janeiro, 1955.

FIBGE. O Brasil: suas riquezas naturais e suas indústrias, 3 vol., 1909. Séries estatísticas retrospectivas. Rio de Janeiro: IBGE, 1986.

REAE/SP. Anuário Estatístico de São Paulo, 1905-1920, São Paulo: Tipografia Espindola \& Comp. (vários anos).

SÃO PAULO. Diário Oficial do Estado de São Paulo. (vários anos).

SÃO PAULO. Junta Comercial de São Paulo (Arquivos). 


\section{Fontes Secundárias}

BAER, W. A industrialização e o Desenvolvimento Econômico do Brasil. Rio de Janeiro: Fundação Getúlio Vargas, 1966.

CANO, W. Raizes da concentração industrial em São Paulo. Tese de doutorado, UNICAMP, Campinas, 1975.

DEAN, W. A industrialização de São Paulo (1880-1945). São Paulo: Difel, 1976.

ERBER, F. S., et alii. Absorção e criação de tecnologia na indústria de bens de capital, Rio de Janeiro: FINEP, 1973.

FISHLOW, A. Origens e consequências da substituição de importações no Brasil. Estudos Econômicos. São Paulo, v. 2, n. 6: 7-75, dez. 1972.

HADDAD, C. L. da S. Crescimento do produto real brasileiro-1900/1947. Revista de Economia Brasileira. Rio de Janeiro, 29 (1): 3-26, jan./mar. 1975.

LAGO, L. A. C. et alii. A indústria brasileira de bens de capital: Origens, situação recente e perspectivas. $1^{a}$ ed., Rio de Janeiro: FGV/IBRE, 1979.

LEFF, N. H. The Brazilian Capital Goods Industry 1929-1964. Cambridge: Harvard University Press, 1968.

LUZ, N. V. A luta pela industrialização do Brasil, 1808 a 1930. São Paulo: Difusão Europeia do Livro, 1961.

MELLO, J. M. C. de M. O Capitalismo Tardio. São Paulo: Brasiliense, 8a . ed., 1991.

PRADO JR., C. História Econômica do Brasil. São Paulo: Editora Brasiliense, 1959.

SILVA, S. Expansão cafeeira e origem da indústria no Brasil. São Paulo: Alfa Omega, 1976.

SIMONSEN, R. A evolução industrial do Brasil. São Paulo: FIESP, 1939.

STEIN, S. J. Origens e evolução da indústria têxtil no Brasil, 1850-1950. Rio de Janeiro: Campus, 1979.

SUZIGAN, W. Indústria Brasileira. Origem e desenvolvimento. 2 ed., São Paulo: Huicitec/Unicamp, 2000.

VERSIANI, F. R.; VERSIANI, M. T. A indústria brasileira antes de 1930: uma contribuição. In: VERSIANI, F. R.; MENDONÇA DE BARROS, J. R. Formação econômica do Brasil: período republicano. São Paulo: Saraiva, 1977.

VILlELA, A. V.; SUZIGAN, W. Política do Governo e Crescimento da Economia Brasileira, 18891945. Rio de Janeiro: IPEA/INPES, 1973. 